\title{
BUOYANCY-DRIVEN FLOW IN ANNULAR SPACE FROM TWO CIRCULAR CYLINDERS IN TANDEM ARRANGEMENT
}

\author{
Houssem Laidoudi * \\ Laboratoire des Sciences et Ingénierie Maritime (LSIM), Faculty of Mechanical \\ engineering, USTO-MB, BP 1505, El-Menaouer, Oran 31000, Algeria
}

Received 24.03.2020

Accepted 05.04.2020

\begin{abstract}
The two-dimensional numerical investigation is well accomplished to understand the behavior of buoyancy-driven flow in closed annular space. The studied domain consists of a pair of equal-sized circular cylinders in tandem arrangement confined in a circular enclosure which is filled with incompressible Newtonian fluid. The inner cylinders are identical in size and they are supposed to be hot with constant temperature, the outer circular enclosure is kept cold with a constant temperature. The descriptive governing equations of continuity, momentum and energy for the present problem are solved numerically using the finite-volume method. The present research studies the effects of thermal buoyancy strength, the thermophysical characteristics of the fluid, and the size of the inner cylinders on the flow patterns inside the circular domain and rate of heat transfer exchanging between the inner cylinders and fluid flow. The results showed that the studied governing parameters significantly affect the fluid flow and heat transfer rate. An increase in the diameter of inner cylinders makes the effect of buoyancy strength on fluid flow and heat transfer negligible for all values of thermo-physical parameters. Also, the average Nusselt number of each inner cylinder is computed and plotted for industrial applications.
\end{abstract}

Keywords: buoyancy-driven flown; natural convection; annular space; two circular cylinders; steady flow; heat transfer; incompressible fluid.

\section{Introduction}

Many research efforts have been oriented directly to study the natural convection heat transfer from a single as well as multiple cylinders in different arrangements. This is due to the wide presence of this mechanism of heat transfer in many industrial applications such as chemical processes, heat exchangers, nuclear reactors, cooling towers, metallurgies, refineries. When the natural convection occurs between two

*Corresponding author: Houssem Laidoudi, houssem.laidoudi@univ-usto.dz 
enclosed cylinders is usually called an annular system [1-3]. Some numerical and experimental works studied the geometrical configurations of the horizontal annulus, the thermophysical parameters of fluid and the strength of thermal buoyancy [4-8]. The previous researches in this field showed that the thermophysical characteristics of the fluids are controlled by a dimensionless number called Prandtl number [9, 10]; for example, the Prandtl number corresponding to the air is 0.71 , water is 7.01 and for certain kinds of polymers are 50 and 100 . Indeed, for the natural convection mechanism, the hot parts of fluid particles become lighter due to the decrease of their density and accordingly, these parts of fluid move upwardly. Generally, the Bousinesq approach is used to modulate the intensity of natural convection. The dimensional number of Rayleigh is used to control the strength of buoyancy-driven flow [11-12]. For natural convection heat transfer from one confined circular cylinder, Hussein [13] studied the effect of walls of outer square enclosure on the flow patterns and heat transfer. At the end of the work, it was concluded that by moving the cylinder downwardly enhances the heat transfer rate. Matin and Khan [14] numerically investigated the effects of thermal buoyancy on the non-Newtonian power-law fluid within two horizontal cylinders of circular cross-section. The results are presented and discussed for the range of these limited conditions: Rayleigh number $\mathrm{Ra}=10^{3}$ to $10^{5}$, Prandtl number $\operatorname{Pr}=10$ to 100 . At fixed geometrical configuration. It was concluded that the Prandtl number has a limited effect on heat transfer when it is above the value 10. Abu-Nada et al. [15] studied the effect volume fraction of nanoparticles on natural convection heat transfer within two concentric cylinders. The obtained result has proofed that the nanoparticles on fluid enhance the heat transfer rated. Tayebi et al. [16] changed the cross-sectional form of the annulus from circular to elliptical. Nasiri et al. [17] introduced the effect of the eccentric cylinder on buoyancy-driven flow. El-Maghlany et al. [18] numerically studied the effects of thermal buoyancy and the rotational movement of the inner cylinder on the fluid flow and heat transfer in annular space. Both cylinder's inner and outer are circular cross-section. The work also examined the eccentricity arrangement of the inner cylinder. Kefayati and Tang [19] carried out numerical research on the elliptical cylinder in a square enclosure. The researchers tested the effect of the geometrical form of the cylinder on the natural convection heat transfer. In other and, for multiple cylinders inside the annular space, Aly [20] numerically investigated the natural convection on nanofluids inside a square enclosure with two heated circular cylinders. The computational domain is considered porous. The cylinders are placed in a tandem arrangement based on the flow direction. Pandey et al. [21] examined the natural convection heat transfer from multiple cylinders of different cross-sections which are confined in a square enclosure.

On the whole, the research touched the influences of Rayleigh number, Prandtl number and the geometrical configurations on the fluid patterns and heat transfer rate. Ragui et al. [22] provided a numerical investigation of natural convection from multiple square cylinders confined inside a square enclosure; the work studied the effect of the Rayleigh number and the geometrical arrangements of the cylinder on the heat transfer rate which is quantified by the Nusselt number. The work is fixed merely for $\operatorname{Pr}=7$.

From the global analyzes of this research dimension, it can be observed that there is no prior work examined the laminar natural convection from two heated circular cylinders inside a cold circular enclose. Therefore, our effort is devoted to giving insights about that. On the whole, the present work is a numerical investigation of buoyancydriven flows from two heated circular cylinders that are placed in a cold circular 
enclosure. The research examines the effects of thermal buoyancy strength (for $\mathrm{Ra}=10^{3}$ to $10^{5}$ ), the Prandtl number ( $\operatorname{Pr}=0.71$ to 100$)$ and the diameter of inner cylinders on the flow patterns and their impact on heat transfer.

\section{Geometrical presentation of the present problem}

The present geometry is schematically illustrated in Fig. 1. It is a circular enclosure of diameter $(\mathrm{H})$ in which two circular cylinders of diameter $(\mathrm{d})$ are placed in a tandem arrangement in the middle. The center of each inner cylinder is in the middle of the half part of the outer enclosure. This situation obligates that the gap distance between the inner cylinders must be $\mathrm{S}=0.5 \mathrm{H}$. The diameters of inner and outer cylinders define the ratio $\mathrm{d} / \mathrm{H}=0.2,0.3$ and 0.4 . The initial conditions of the investigation are that the inner cylinders are maintained heated with constant temperature $\left(T_{h}\right)$, and the surface of the outer enclosure is kept cold with constant temperature $\left(\mathrm{T}_{\mathrm{c}}\right)$. The annular space between cylinders is filled with incompressible Newtonian fluid.

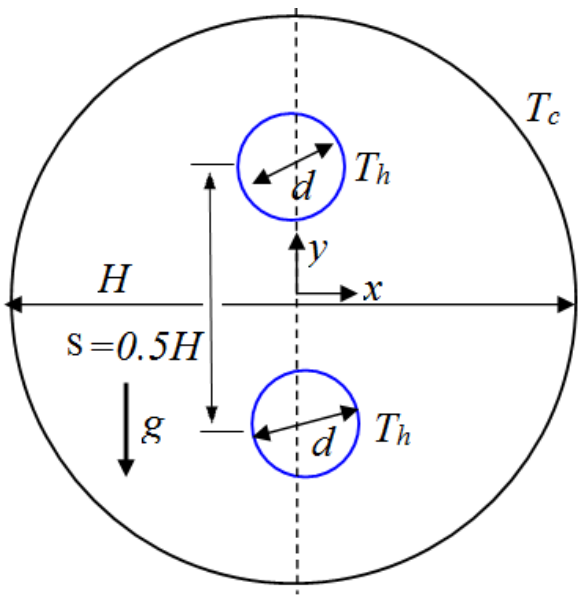

Fig.1. Schematic of present studied geometry.

\section{Governing equations and boundary conditions}

The present investigation is considered for laminar and steady-state flow. The governing equations of continuity, momentum, and energy are solved in two-dimensions in a Cartesian coordinate system. The effect of temperature on momentum is treated concerning Boussinesq approximation. The partial differential equations of present physical problem are written in dimensionless form as:

$$
\begin{aligned}
& \frac{\partial u^{\bullet}}{\partial x^{\bullet}}+\frac{\partial v^{\bullet}}{\partial y^{\bullet}}=0 \\
& u^{\bullet} \frac{\partial u^{\bullet}}{\partial x^{\bullet}}+v^{+} \frac{\partial u^{\bullet}}{\partial y^{\bullet}}=-\frac{\partial p^{\bullet}}{\partial x^{\bullet}}+\operatorname{Pr}\left(\frac{\partial^{2} u^{\bullet}}{\partial x^{\bullet 2}}+\frac{\partial^{2} u^{\bullet}}{\partial y^{\bullet 2}}\right)
\end{aligned}
$$




$$
\begin{aligned}
& u^{\bullet} \frac{\partial v^{\bullet}}{\partial x^{\bullet}}+v^{\bullet} \frac{\partial v^{\bullet}}{\partial y^{\bullet}}=-\frac{\partial p^{\bullet}}{\partial y^{\bullet}}+\operatorname{Pr}\left(\frac{\partial^{2} v^{\bullet}}{\partial x^{\bullet 2}}+\frac{\partial^{2} v^{\bullet}}{\partial y^{\bullet 2}}\right)+R a . \operatorname{Pr} . T^{\bullet} \\
& u^{\bullet} \frac{\partial T^{\bullet}}{\partial x^{\bullet}}+v^{\bullet} \frac{\partial T^{\bullet}}{\partial y^{\bullet}}=\left(\frac{\partial^{2} T^{\bullet}}{\partial x^{\bullet 2}}+\frac{\partial^{2} T^{\bullet}}{\partial y^{\bullet 2}}\right)
\end{aligned}
$$

where $\mathrm{Ra}$ and $\mathrm{Pr}$ are the Rayleigh and Prandtl numbers. These numbers are expressed as follows:

$$
R a=\frac{g \beta\left(T_{h}-T_{c}\right) d^{3}}{v \alpha}, \operatorname{Pr}=\frac{v}{\alpha}
$$

The variables of velocity components $(\mathrm{u}),(\mathrm{v})$, pressure $(\mathrm{p})$, and temperature $(\mathrm{T})$ shown in the governing equations are written in dimensionless form by the following changes:

$$
x^{\bullet}=\frac{x}{d}, y^{\bullet}=\frac{y}{d}, u^{\bullet}=\frac{u d}{\alpha}, v^{\bullet}=\frac{v d}{\alpha}, p^{\bullet}=\frac{p d^{2}}{\rho \alpha^{2}}, T^{\bullet}=\frac{T-T_{c}}{T_{h}-T_{c}}
$$

The thermophysical characteristics of the fluids used for present investigation are denoted by following Greek letters the fluid density is $\rho$, kinematic viscosity is $v$, thermal diffusivity is $\alpha$, and the expansion coefficient is $\beta$. Where $g$ is the acceleration gravitation.

The local and average values of Nusselt number on the surface of inner cylinders are computed based on the following expressions respectively:

$$
\begin{aligned}
& N u_{l}=\left.\frac{\partial \phi}{\partial n}\right|_{\text {wall }} \\
& N u=\frac{1}{s} \int_{0}^{s} N u_{l} d s
\end{aligned}
$$

where $\mathrm{n}$ and $\mathrm{s}$ are the directions normal to the wall and the length of the inner cylinder surface.

The suitable boundary conditions for present geometry are:

On the surfaces of inner cylinders; heated surfaces with no-slip boundary layer as:

$$
u^{\bullet}=0, v^{\bullet}=0, T^{\bullet}=1
$$


On the surface of the outer cylinder: a cold surface with no-slip boundary layer as:

$$
u^{\bullet}=0, v^{\bullet}=0, T^{\bullet}=0
$$

\section{Numerical methodology and validation test}

The partial differential equations of continuity, momentum, and energy are solved numerically by using the package called ANSYS-CFX. The present software employs the numerical finite-volume method to transform the governing equations into a system of the discrete algebraic system under the form of a matrix. The convective terms of the algebraic system are solved by using High resolution discretization scheme. For velocitypressure coupling, the numerical algorithm of SIMPLEC (Semi-Implicit Method for Pressure-Linked Equations-Consistent) is used for that reason. The convergence criteria describing the relative error of governing equations are considered $10^{-8}$ for the discretized continuity and momentum equations and $10^{-6}$ for the discretized energy equation. The software Gambit is also used for the creation of geometries with a comfortable grid. Fig. 2 shows one case of the grid for ratio $\mathrm{d} / \mathrm{H}=0.3$. For all considered cases, the grid is generated with unstructured mesh with non-uniform concentrations of cellular elements. The elements are consecrated around the inner cylinders. Table 1 summarizes the cellular elements of each geometry with respect to the value of ratio $\mathrm{d} / \mathrm{H}$. these elements are selected after a satisfactory study of grid independency test which is not reported here for the sake of brevity.

For any computational investigation, it is necessary to prove the accuracy of the numerical methodology. For that reason, we have repeated the same investigations of Kuehn and Goldstein [23] and Matin and Khan [14]. The first one is experimental and the second is numerical. The comparison test is about the natural convection between two concentric cylinders of circular cross-section. Fig. 3 shows a comparison between the present and prior results. A good agreement is seen between all results.

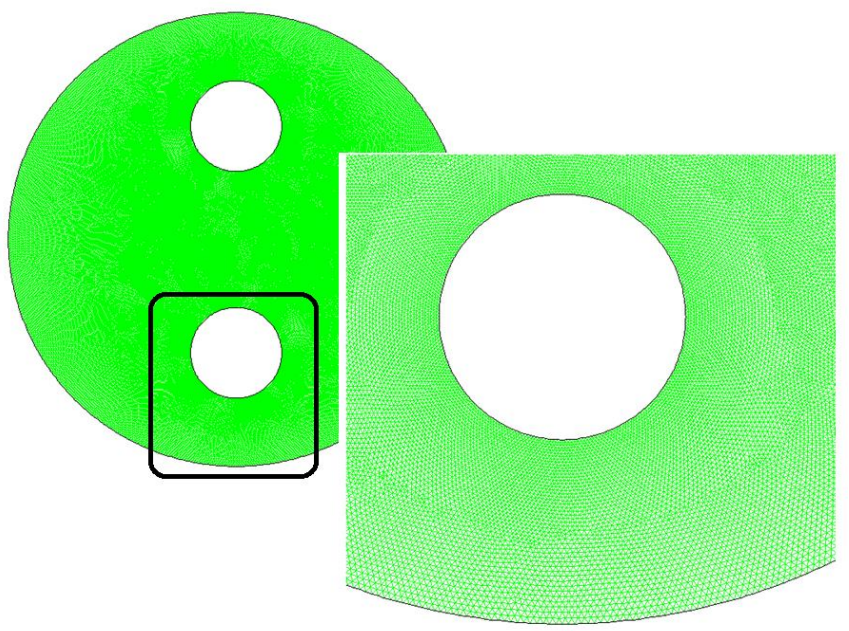

Fig. 3. Grid used for present work. 
Table1. The grid elements for each geometry.

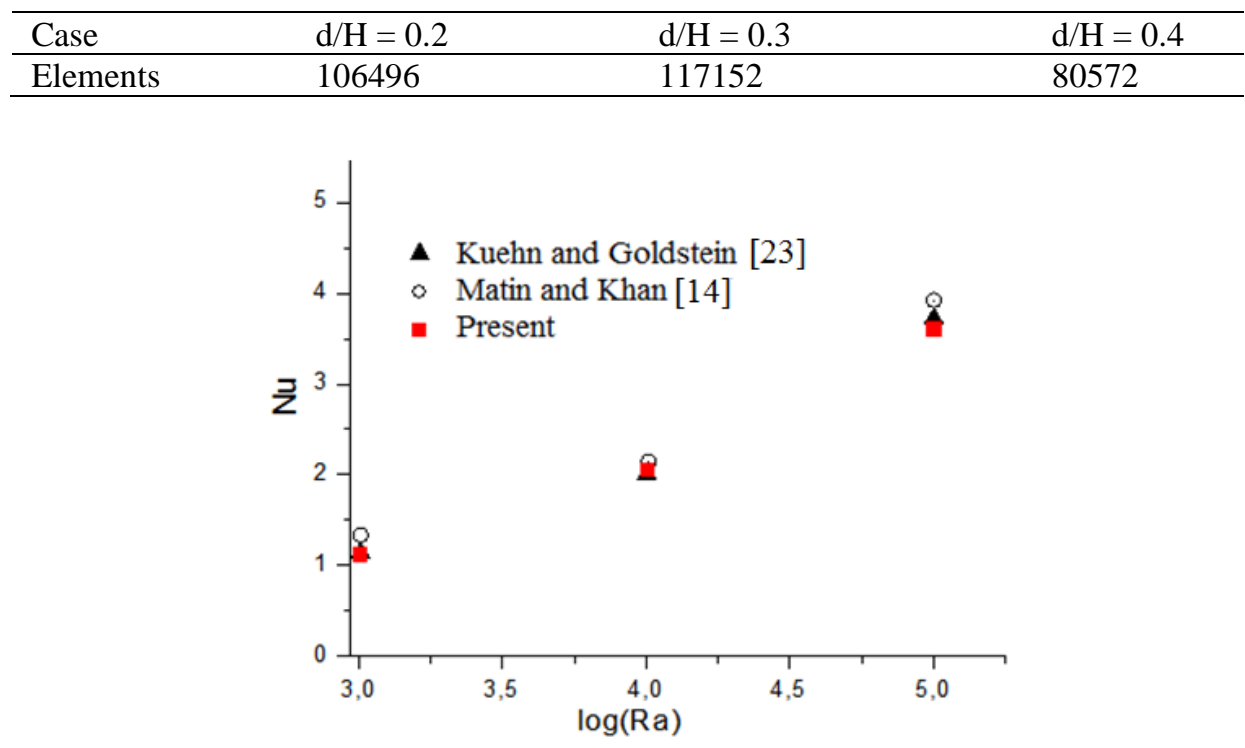

Fig. 3. Comparison of average Nusselt number for concentric annulus of $R R=2.5$ and $\operatorname{Pr}=1$.

\section{Results and discussion}

The present work is devoted to understanding the effects of Rayleigh number $\left(\mathrm{Ra}=10^{3}\right.$ to $\left.10^{5}\right)$, Prandtl number $(\mathrm{Pr}=0.71$ to 100$)$ and the diameter of inner cylinders $(\mathrm{d} / \mathrm{H}=0.2,0.3$ and 0.4$)$ on laminar natural convection from tow circular cylinder in tandem arrangement confined in a circular enclosure. The main results are shown in terms of representative streamlines and isotherms to predict the evolutions of flow patterns and temperature distributions under the progressive change of the above governing parameters. Also, this section represents the evolutions of the dimensionless velocity component and dimensionless temperature along the vertical and horizontal middle of the entire enclosure. The quantities values of the average Nusselt number of both cylinders are also calculated and presented.

Fig. 4 shows the effects of studied parameters $(\mathrm{d} / \mathrm{H}, \mathrm{Ra}$, and $\mathrm{Pr})$ on the streamline contours. Fig.4 (a) is for $\mathrm{d} / \mathrm{H}=0.2,0.3$ and 0.4 and for $\mathrm{Ra}=10^{3}$ to $10^{5}$ at fixed $\mathrm{Pr}=7.01$. Fig. 4 (b) is for the same parameters but $\operatorname{Pr}=50$. It is clear that for all cases, the streamlines are perfectly symmetric concerning the vertical line $(y=0)$. This confirms that the effect of thermal buoyancy on fluid flow for studied parameters generates only steady-state phenomena. Under the effect of thermal buoyancy, the fluid particles are in the vicinity of inner hot cylinders become lighter and they move up toward the cold surface of the outer enclosure. Concurrently, the fluid particles are beside the cold outer recipient become heavier and then move down due to gravitational force. As a consequence, a rotating flow appears inside the annular space of the domain as it is depicted in Fig. 4. The center of the counter-rotating flow is in the middle of half side of space for $\mathrm{Ra}=10^{3}$ and when we increase the value from $\mathrm{Ra}=10^{3}$ to $10^{5}$ the center of 
rotating flow moves toward the side of hot cylinders. The displacement of the recirculation center, toward the center between the cylinders, changes the shape of the recirculation zone from a circular shape to a stretched circular shape. Also, for $\mathrm{d} / \mathrm{H}=0.2$, the increase in Ra number creates a small counter-rotating next to the outer cylinder. Globally, it can be remarked that increases in the value of Rayleigh number increase the intensity of flow inside a domain and this because by increasing Rayleigh number the effect of thermal buoyancy becomes significant and the flow velocity increases. Accordingly, the inertia of the flow becomes very remarkable. In another hand, it is seen that for each ratio $\mathrm{d} / \mathrm{H}$ increase in Prandtl number makes the flow more stable and this effect can be explained as when the Prandtl number of fluid was increased that means the kinematic viscosity becomes more pronounced and according to the flow is more stable. It is also observed that an increase in the ratio $\mathrm{d} / \mathrm{H}$ makes the flow more stable. Furthermore, the increase in the diameter of inner cylinders makes the effects of Rayleigh and Prandtl numbers almost negligible.

(a)

$\mathrm{d} / \mathrm{H}=0.2$
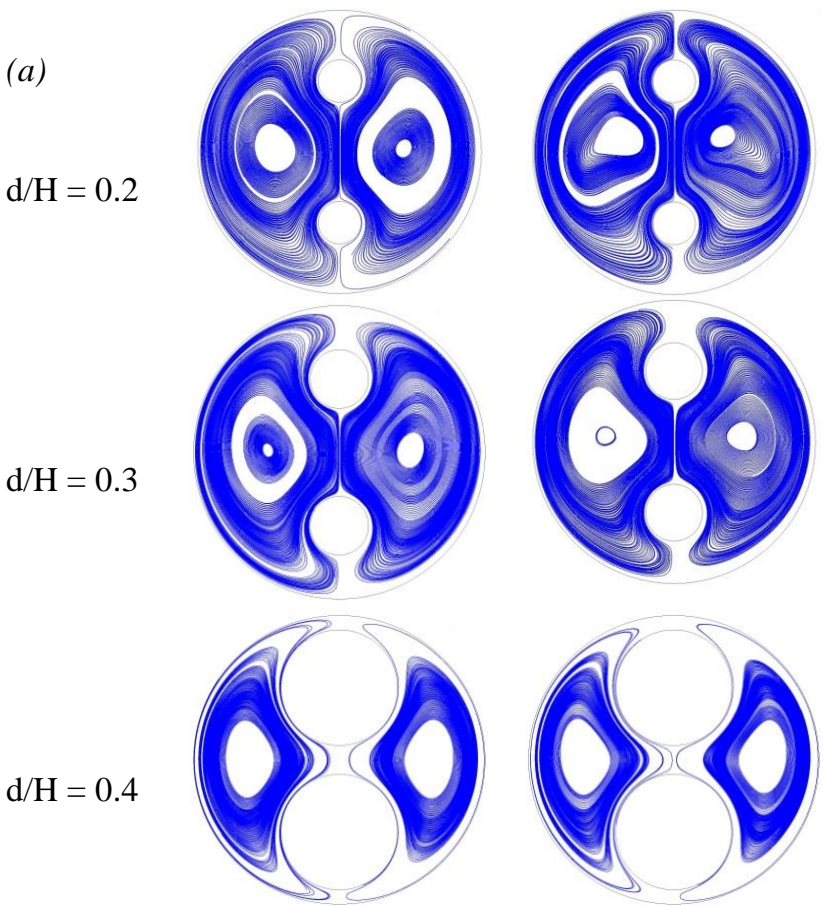

$\mathrm{Ra}=10^{3}$

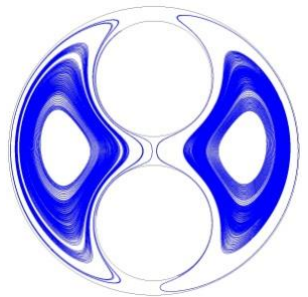

$\mathrm{Ra}=10^{4}$
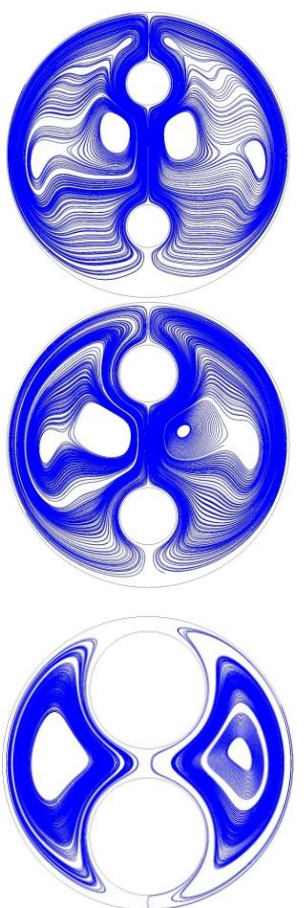

$\mathrm{Ra}=10^{5}$ 
(b)
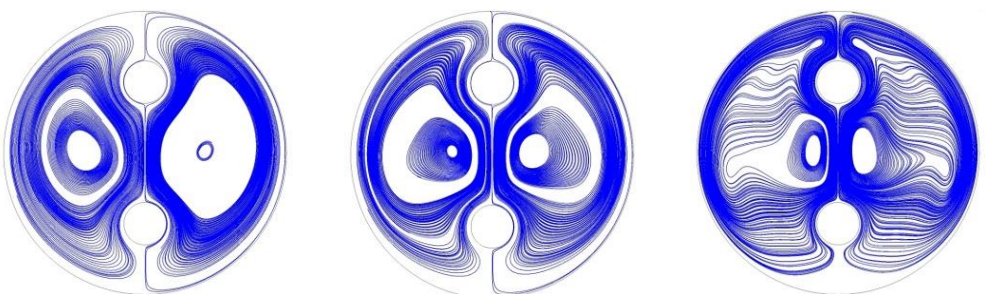

$\mathrm{d} / \mathrm{H}=0.2$
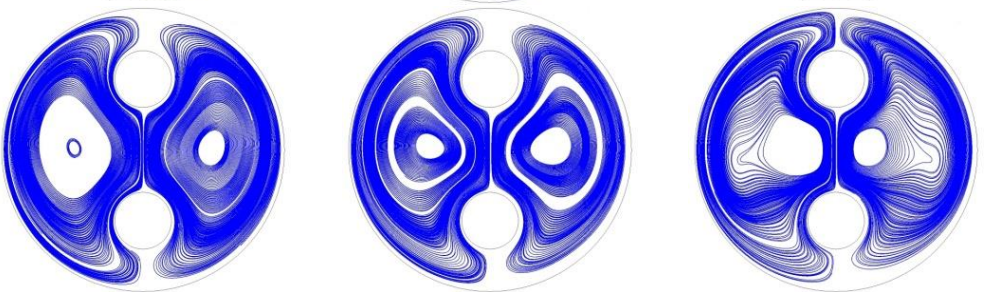

$\mathrm{d} / \mathrm{H}=0.3$
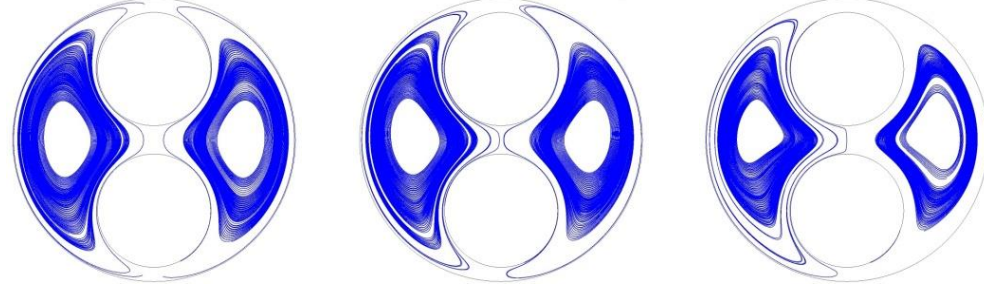

$$
\mathrm{Ra}=10^{3}
$$

$$
\mathrm{Ra}=10^{4}
$$

$$
\mathrm{Ra}=10^{5}
$$

Fig. 4. Streamlines for different values of $d / H$ and $R a$, (a) at $\operatorname{Pr}=7.01$, (b) at $\operatorname{Pr}=50$.

In order to justify the explanations of streamline contours, Fig. 5 depicts the variation of velocity profiles along the $y$-direction for $(x=0)$ versus Rayleigh number at $\operatorname{Pr}=50$ for different values of $\mathrm{d} / \mathrm{H}$. it is clear that for all values of $\mathrm{d} / \mathrm{H}$, an increase in Rayleigh number increases the velocity component. Also, an increase in the diameter of inner cylinders reduces the velocity of the flow along the y-direction. 

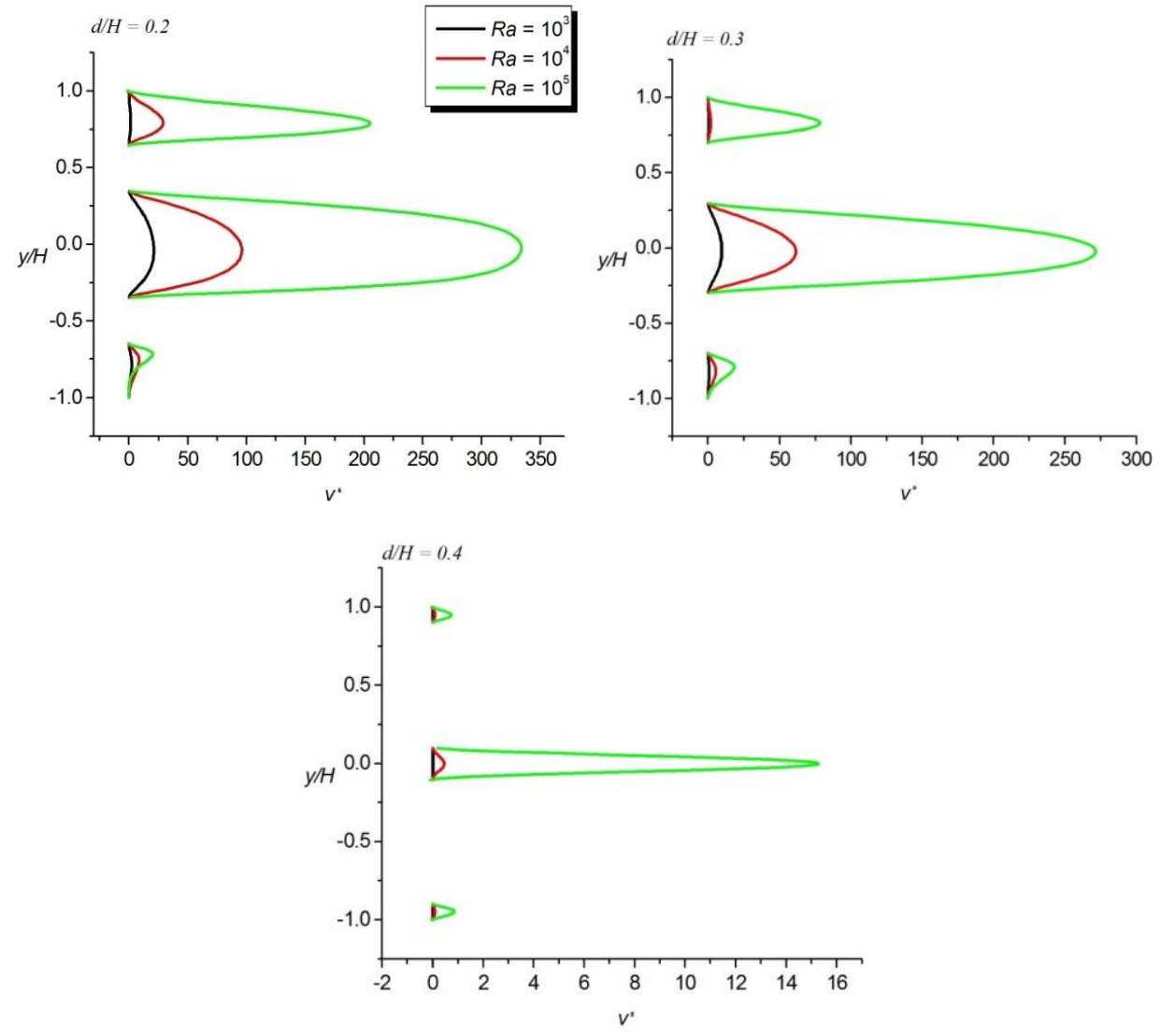

Fig.5. Dimensionless velocity profiles along the $y$-direction for different values of $R a$ and $d / H$ at fixed $\mathrm{Pr}=50$.

Fig. 6 shows the distribution of dimensionless velocity profiles along the ydirection at $(\mathrm{x}=0)$ and along the $\mathrm{x}$-direction at $(\mathrm{y}=0)$ versus Prandtl number and ratio $\mathrm{d} / \mathrm{H}$. Along the $\mathrm{y}$-direction, an increase in Pr increases the velocity until the 50 then it becomes constant. The maximum value of velocity is always between the inner cylinders. The values of velocity decrease significantly with increasing the diameter of the inner cylinder. Along the $\mathrm{x}$-direction, the maximum value of velocity is in the middle of the domain. The effects of $\operatorname{Pr}$ on velocity profiles are almost negligible for $\mathrm{d} / \mathrm{H}=0.4$. Also, the velocity of hot particles of fluid is greater than the velocity of cold particles in the opposite direction. 

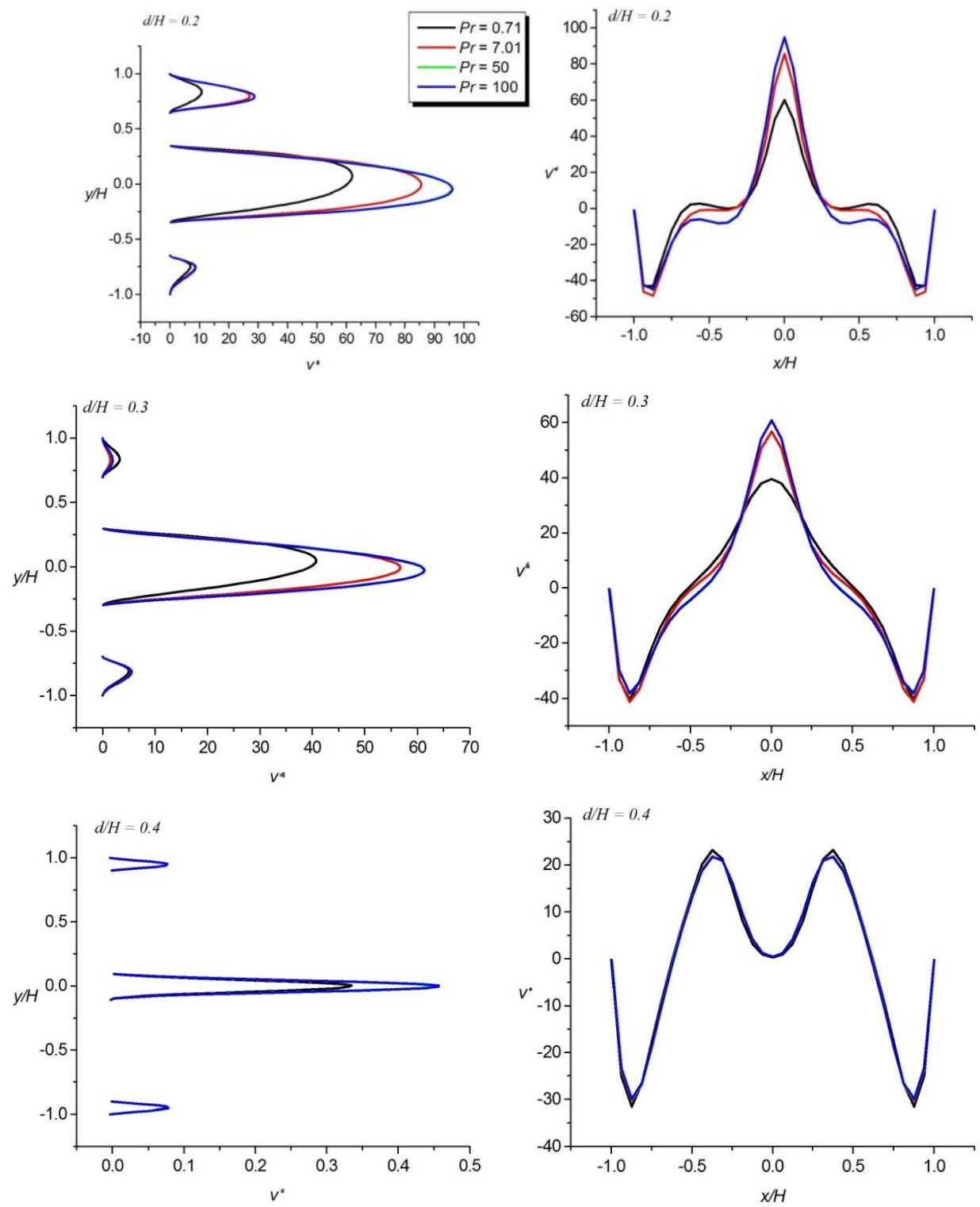

Fig.6. Dimensionless velocity profiles along $x$ and $y$ direction for different values of $P r$ and $d / H$ at a fixed value of $\mathrm{Ra}=10^{4}$.

Fig. 7 shows representative isothermal contours of dimensionless temperature for the same governing parameters as the streamline contours. For both cylinders, a plume of isotherms appears on the crown of inner cylinders to indicating the direction of fluid motion. For almost cases, the density of isotherms appears smaller around the bottom cylinder than the top cylinder. This effect indicates that the thickness of the thermal boundary layer of the bottom cylinder is more critical than the top cylinder. 
As a consequence, the heat transfer rate of the bottom cylinder should be more important than the top cylinder. This is since the cold source of fluid is always at the lower part of the domain. Therefore, the heat exchanging of the bottom cylinder is better than the top cylinder. For all geometrical configurations, an increase in the value of the Rayleigh number decreases the thickness of the thermal boundary layer around both cylinders. This is due to the fluid velocity which increases with increasing the buoyancy strength. The effect of the Prandtl number on isotherms is almost negligible.

On the other hand, the increase in the diameters of the cylinder has a significant impact on isotherms. Finally, it can be concluded that an increase in the diameter of inner cylinders decreases the heat transfer rate. This information can be useful for the insulting application. On the other hand, a decrease in the diameter of the inner cylinders enhances the heat transfer rate. This point is efficient for cooling purposes.

(a)
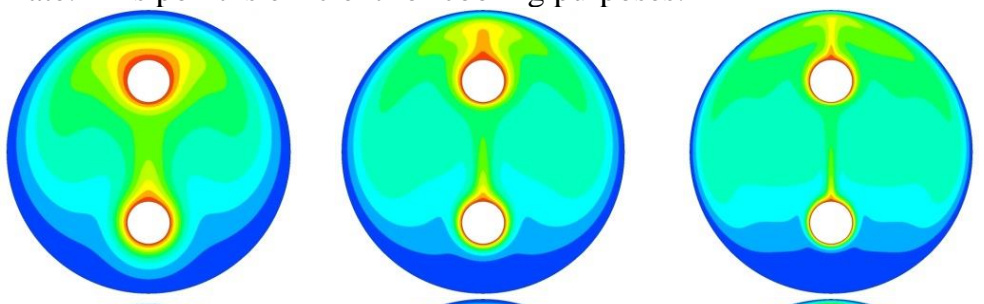

$\mathrm{d} / \mathrm{H}=0.3$
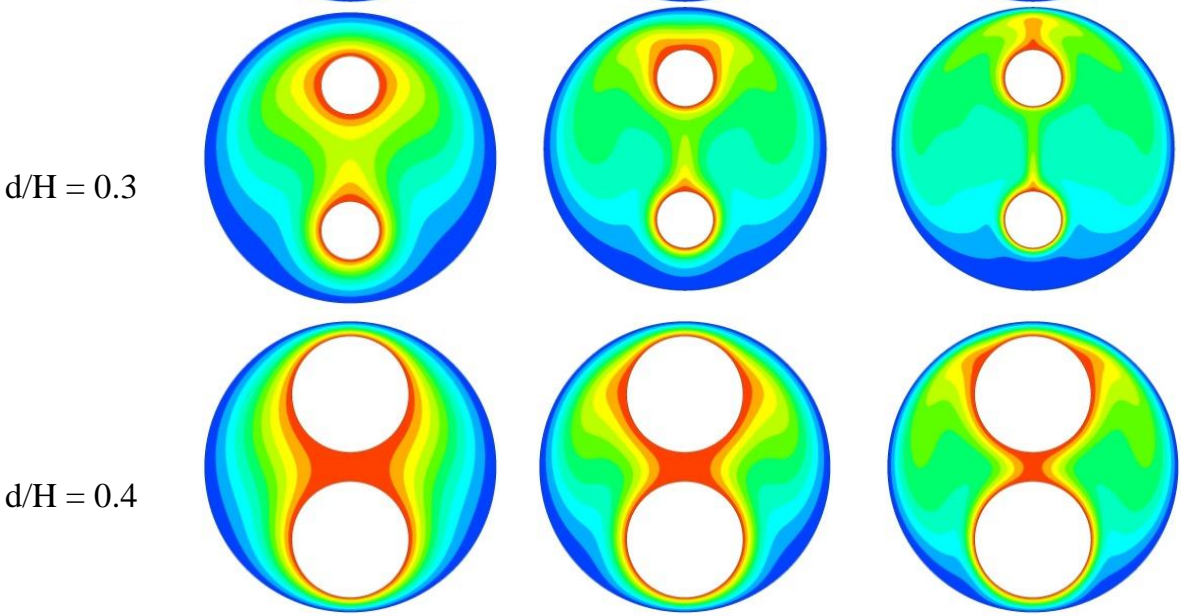

$\mathrm{Ra}=10^{3}$

$\mathrm{Ra}=10^{4}$

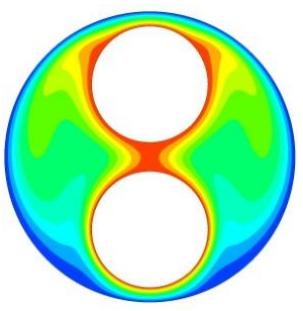

$\mathrm{Ra}=10^{5}$ 

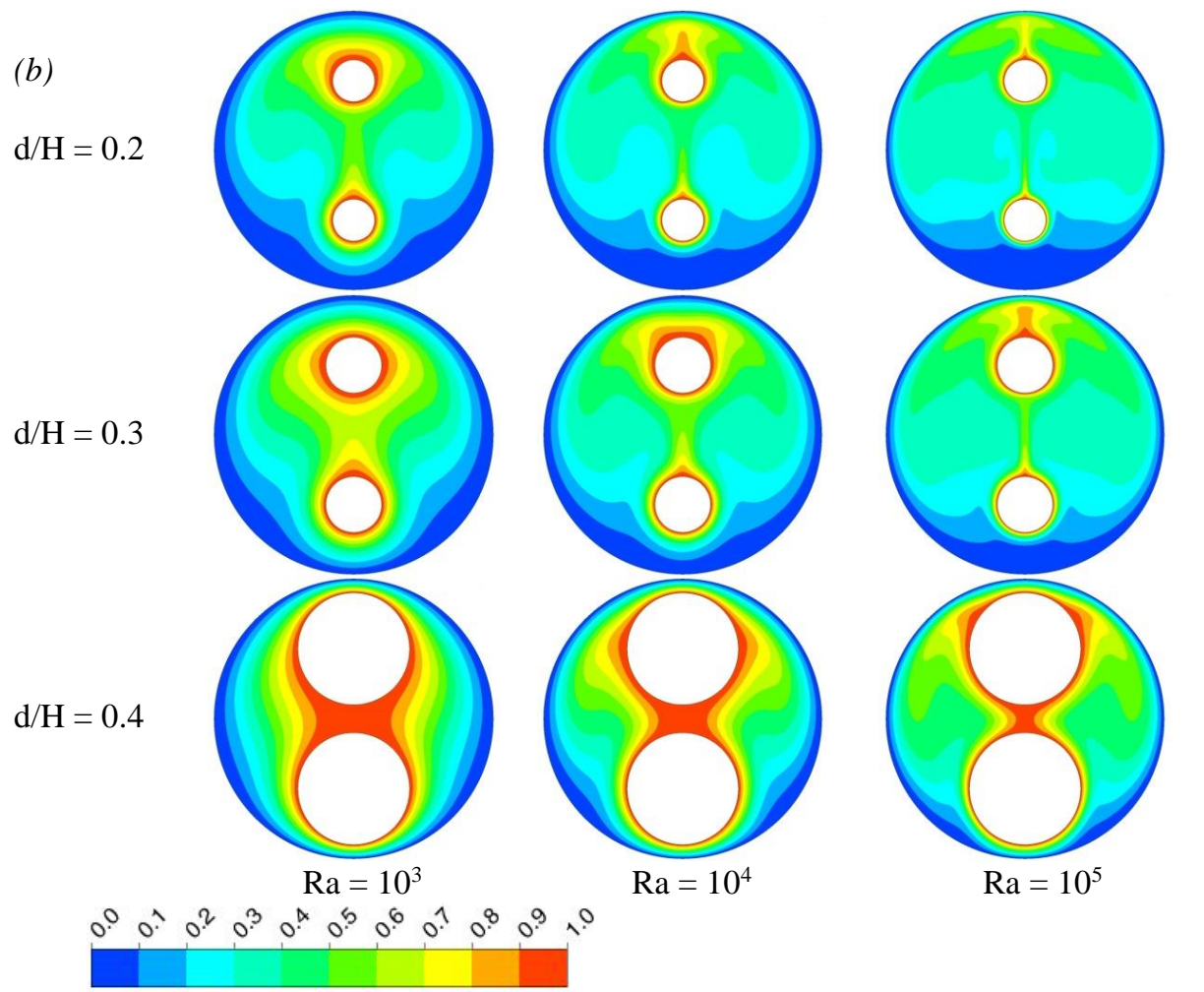

Fig.7. Isotherms for different values of $d / H$ and $R a$, (a) at $\operatorname{Pr}=7.01$, (b) at $\operatorname{Pr}=50$. 

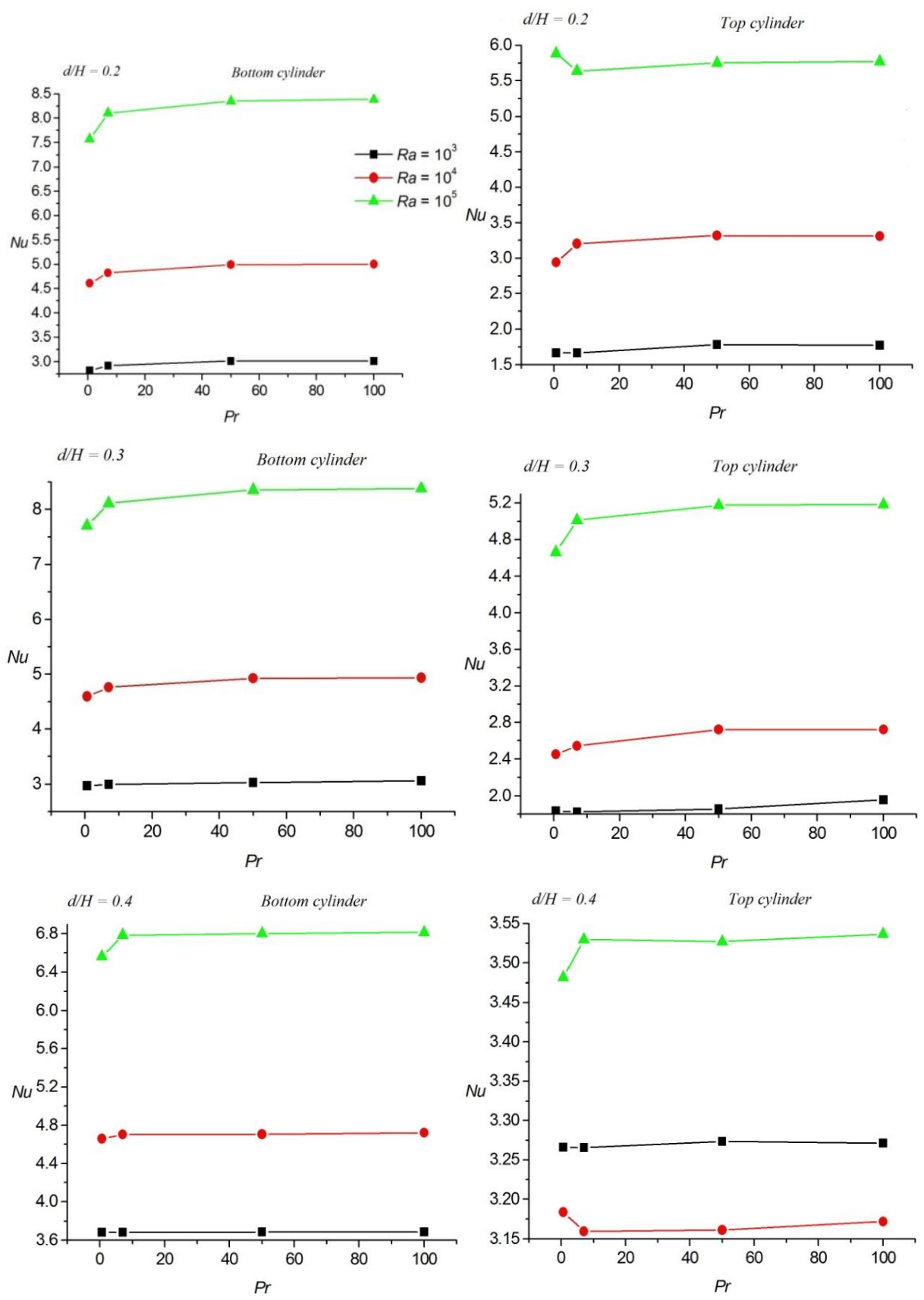

Fig. 8. Variation of average Nusselt number versus Prandtl number for different values of $\mathrm{Ra}$ and $\mathrm{d} / \mathrm{H}$. 
Fig. 8 shows the variations of average Nusselt number of both cylinders as a function of Prandtl number, Rayleigh number and the ratio $\mathrm{d} / \mathrm{H}$. It is clear that for studied cases, the increase in Ra number increases the average Nusselt number. Therefore, an increase in the rate of heat transfer. As it was expected from the analyses of isotherms, the average Nusselt number of bottom cylinder id greater than the top cylinder for all diameters. It can also be observed that the effect of Prandtl number on average Nusselt number of both cylinders is almost negligible, especially over the value 7.1. For all governing parametrical values of Prandtl and Rayleigh number, the increase in the diameters of inner cylinders reduces the value of Nusselt number of cylinders. It is observed only for one case for the top cylinder and when $\mathrm{d} / \mathrm{H}=0.4$ and for all values of Prandtl number increase in $\mathrm{Ra}$ from $10^{3}$ to $10^{4}$ decreases a little the average Nusselt number.

\section{Conclusion}

The present investigation is devoted to studying the laminar buoyancy-driven flow from two circular cylinders placed in the tandem arrangement within a circular enclosure. The work studies the effects of Rayleigh number, Prandtl number and the diameter of inner cylinders on the flow patterns and heat transfer. These new discussed results can be useful for the engineering applications of cooling and insulting. At the end of this research, some concluded points are determined:

- An increase in the value of the Rayleigh number enhances the heat transfer rate for all cases, exempt one case for $\mathrm{d} / \mathrm{H}=0.4$ and $\mathrm{Ra}=10^{4}$.

- The effect of Prandtl number on fluid flow and heat transfer rate of cylinders is negligible over the value 7.1 .

- An increase in the diameter of inner cylinders reduces the effect of thermal buoyancy in the studied domain.

- Decrease the diameter of inner cylinders increases the flow inside the annular space.

- The present work shows that the fluid flow and heat transfer for this investigation have a steady-state regime.

- Unlike a single inner cylinder in annular space, the double cylinders in tandem arrangement always keep the center of counter-rotating flow in the middle of geometry.

- For almost studied geometries, the highest value of the local velocity of the flow is in the middle of the domain between the cylinders. 


\section{Nomenclature}

\begin{tabular}{|c|c|c|c|}
\hline$d$ & diameter of inner cylinders [m] & $u$ & velocity along $\mathrm{x}$ direction $[\mathrm{m} / \mathrm{s}]$ \\
\hline$H$ & diameter of outer cylinder $[\mathrm{m}]$ & $v$ & velocity along y direction $[\mathrm{m} / \mathrm{s}]$ \\
\hline$g$ & gravity acceleration $\left[\mathrm{ms}^{-2}\right]$ & $x$ & $\mathrm{x}$-coordinate $[\mathrm{m}]$ \\
\hline$n, s$ & normal direction [-] & $y$ & $\mathrm{y}$-coordinate $[\mathrm{m}]$ \\
\hline$N u_{l}$ & average Nusselt number [-] & \multicolumn{2}{|c|}{ Greek symbols } \\
\hline $\mathrm{Nu}$ & local Nusselt number [-] & $\alpha$ & thermal diffusivity $\left[\mathrm{m}^{2} / \mathrm{s}\right]$ \\
\hline$p$ & pressure $[-]$ & $\beta$ & $\begin{array}{l}\text { coefficient of volume expansion } \\
{\left[\mathrm{K}^{-1}\right]}\end{array}$ \\
\hline $\operatorname{Pr}$ & Prandtl number [-] & $v$ & kinematic viscosity $\left[\mathrm{m}^{2} / \mathrm{s}\right]$ \\
\hline u & Rayleigh number, [-] & $\rho$ & density of fluid $\left[\mathrm{kg} / \mathrm{m}^{3}\right]$ \\
\hline$T$ & temperature $[\mathrm{K}]$ & \multicolumn{2}{|c|}{ Superscripts } \\
\hline$T$ & cold temperature $[\mathrm{K}]$ & . & dimensionless quantity \\
\hline & hot temperature $[\mathrm{K}]$ & & \\
\hline
\end{tabular}

\section{References}

[1] T. Zhang, Q.Tang, H. Lu, S. Wang, L. Sun: J RSC Adv, 5 (2015) 12178-12185.

[2] K. N. Volkova, A. G. Karpenko: J Engineering Physics Thermophysics, 87 (2014) 929-235.

[3] M. Venkatachalappa, M. Sankar and A. A. Natarajan: Acta Mechanica, 147(2001) 173-196.

[4] S. Touzani, A. Idrissi, A. Cheddadi, M. T. Ouazzani: J Engineering Physics Thermophysics, 92 (2019) 1064-1071.

[5] G.A. Sheikhzadeh, M. Arbaban, M. A. Mehrabian: Heat Mass Transfer, 49 (2013) 391-403.

[6] N. Scurtu, B. Futterer, Ch. Egbers: Journal of Physics: Conference Series, 137 (2008) 012017.

[7] S. A. Nada: Heat Mass Transfer, 44 (2008) 929-936.

[8] A. Mezrhab, M. A. Moussaoui, H. Naji: J. Phys. D: Appl Phys, 41 (2008) 115502 (17pp).

[9] F. Mebarek-Oudina, R. Bessaïh: Thermophysics and Aeromechanics, 26 (2019) 325-334.

[10] N. Kozlov: Fluid Dyn Res, 50 (2018) 051402 (12pp).

[11] Eldesouki Ibrahim Eid: Heat Mass Transfer, 47 (2011) 81-91.

[12] K.F.U. Ahmed, R. Nasrin, M. Elias: J Naval Architecture Marine Engineering, 15 (2018) 37-52.

[13] A.K. Hussein: Comm Heat Mass Transfer, 46 (2013) 126-133.

[14] M. H. Matin, W. A. Khan: Comm Heat Mass Transfer, 43 (2013) 112-121.

[15] E. Abu-Nada, Z. Masoud, A. Hijazi: Comm Heat Mass Transfer, 35 (2008) $657-$ 665.

[16] T. Tayebi, A.J. Chamkha, M. Djezzar, A. Bouzerzour: J Thermal Science Engineering Applications, 9 (2017) 011010-1.

[17] D. Nasiri, A.A. Dehghan, M.R. Hadian: Heat Mass Transfer, 53 (2016) 799-811. 
[18] W. El-Maghlany, Mohamed Abo Elazm, Ali Shahata, Yehia Eldrainy: Thermal Science, 20 (2016) 1597-1608.

[19] GH.R. Kefayati, H. Tang: Heat Mass Transfer, 120 (2018) 731-750.

[20] A. M. Aly: Taiwan Institute of Chemical Engineers 70 (2017) 88-103.

[21] S. Pandey, Y. G. Park, M. Y. Ha: Heat Mass Transfer, 138 (2019) 762-795.

[22] K. Ragui, A. Boutra, Y. K. Benkahla: Letters of Chemistry, Physics Astronomy, 64 (2018) 144-158.

[23] T.H. Kuehn, R.J.Goldstein: J Fluid Mechanics, 74 (1976) 695-719.

\section{(c) (†) Creative Commons License}

This work is licensed under a Creative Commons Attribution 4.0 International License. 